\author{
Daniel Pattier* \\ Complutense University of Madrid \\ Department of Educational Studies
}

\title{
EDUCATING IN ART AND CULTURE THROUGH YOUTUBE: THE IMPACT OF EDUTUBERS
}

\author{
Original scientific paper \\ UDC 374:004.738.5 \\ $008+7.03$ \\ https://doi.org/10.18485/kkonline.2021.12.12.10
}

YouTube is one of the most used communication technology platforms in education today. The objective of our research is to study the quantitative impact and the most important variables of the educational channels of the Art and Culture area. Thanks to the analysis of the 39 most successful YouTube Spain educational channels framed in this area of knowledge, we obtain significant results on the following dimensions: channel statistics, video statistics, features of the videos, channel options and other social networks. We conclude that there is currently a high quantitative impact of these channels on informal education, but a negative future projection is evident. Finally, the success factors of the channels and the most important characteristics of the edutubers of the Art and Culture area are highlighted. Our research provides valuable data for researchers and professionals in communication, education, and the areas of Art and Culture.

Key words: art education, communication, culture, educational video, edutubers, informal learning, Youtube

\section{Introduction}

The arrival of the YouTube platform in 2005 caused a change in the trend in the use of audiovisual resources in all areas of society. At present, this technological application is one of the most used in the educational field (Rangarajan et al. 2019) and reaches an international impact, at least from a quantitative point of view, (Pattier 2021A) from a formal (Sarkar et al. 2019) and informal perspective (Rosenthal 2018). The literature shows us the positive assessment of the use of YouTube in education by teachers (Srinivasacharlu 2020) and students (Díaz et al. 2020) in the teaching-learning process. The implementation of audiovisual resources offered by this technological application in the educational field manages to improve the motivation of students (Fenyvesi 2020), enhance their self-taught ability (Ranga 2017), and even increase academic performance (Veytia Bucheli et al. 2020) due to its usefulness

\footnotetext{
* Complutense University of Madrid, Faculty of Education, C/ Rector Royo-Villanova, 28040 Madrid, Spain; e-mail: dpattier@ucm.es
} 
(Laugerman \& Saunders 2019) or the ability of these resources to propose real examples and contexts or the explanation of concepts (Tiernan \& O 'Kelly 2019).

However, it is important to point out that there is also literature that indicates the disadvantages of this type of implementation in the educational field (Macias-Silva et al. 2020), such as the loss of the following factors: the attention by students (Zureick et al. 2018), the necessary rigor in education (Beltrán-Pellicer et al. 2018), the central objectives of the course (Esparza Puga 2018) or the control of the class during the implementation of the videos (Behesti et al. 2018).

Regarding the field of study of the Art and Culture area, the literature shows us that the use of YouTube has managed to exponentially increase the number of people interested in training in these topics (Parrish 2016). In addition, its use has been integrated into training plans from a formal perspective (Clark et al. 2019), reducing the problems associated with the presence of lessons through the creation of video tutorials on the subject (Hopper 2016) and promoting the emergence and development of such an important dimension in this area as creativity (Duncum 2018).

On the other hand, the digital context in which we currently operate has led to the appearance of people who disseminate knowledge through the YouTube platform: edutubers (López et al. 2020), who manage to reach a large audience through their YouTube channels (Vizcaíno-Verdú et al. 2020). In this area, we find research on the statistical data offered by YouTube (Saurabh \& Gautam 2019), the success and quantitative impact factors of the educational channels of the platform (Pattier 2021A), and the analysis of instruments and rubrics for the YouTube video evaluation (Neumann \& Herodotou 2020).

Therefore, the objective of our research is to analyze the educational YouTube channels of the Art and Culture area through the following research questions: (1) What is the quantitative impact and current trend of the educational YouTube channels of Art and Culture? (2) How do edutubers who disseminate knowledge about Art and Culture behave within the YouTube platform and on other social networks?

\section{Method}

In order to answer our research questions, and obtain data on the quantitative impact and on the dynamics of creating videos of the edutubers of the Art and Culture area, an ad hoc instrument for the analysis of educational YouTube channels from any area of knowledge was developed, taking into account the study dimensions that can be publicly evaluated on the platform. The instrument received the validation of 
experts from the areas of education, communication and research. In addition, the validity and reliability of each item of analysis was verified through Aiken's $V$ coefficient.

For the selection of the sample, the following variables that the YouTube channels had to fulfil were determined: the nature of the YouTube channels had to be clearly educational; the area of knowledge disclosed by the edutuber had to be notorious about Art and Culture; channels from YouTube Spain were taken into account; and a quantification of the channel's statistics was stipulated that would denote significant success within the YouTube platform, estimating for the sample the channels that exceeded 1,000 subscribers (YouTube Opal level) and the 300,000 total views of the channel's videos, as shown in Table 1.

Table 1

Correspondence by ranges of years between the channel creation date and the start of uploading the videos

\begin{tabular}{ll}
\hline Variables & Requirement \\
\hline Typology & Educational YouTube channels \\
Knowledge area & Art and culture \\
Country & Spain \\
Number of subscribers & At least 1,000 subscribers \\
Number of views & At least 300,000 views \\
Content creator & Particular \\
\hline
\end{tabular}

Source: Own elaboration

The data obtained were analysed through the SPSS 25.0 program.

Therefore, 39 channels were found that met the stipulated requirements and that make up the sample for our study. These 39 Art and Culture channels make up 19.1\% of all educational channels in any area that exceeded the established parameters. Regarding the characterization of this sample, it stands out that $64 \%$ are channels directed by men while $36 \%$ are directed by women. In addition, if we take into account the ages to which the YouTube Art and Culture channels are aimed, we can see that they are focused on the stage of Early Childhood Education (23.1\%), Primary $(12.8 \%)$, Secondary or Baccalaureate $(12.8 \%)$ or to any specific stage $(51.3 \%)$, while there are no educational channels focused on the Professional Training or at the University stage. 
In this article, we show the dimensions and items related to our research questions, as shown in Table 2:

Table 2

Correlation between the research questions and the dimensions and items analysed

\begin{tabular}{|c|c|c|}
\hline $\begin{array}{l}\text { Research } \\
\text { question }\end{array}$ & Dimensions & Items \\
\hline 1 & Channel statistics & $\begin{array}{l}\text { Number of subscribers. } \\
\text { Number of views. } \\
\text { YouTube channel creation date. } \\
\text { Start date of uploading videos to the } \\
\text { channel. }\end{array}$ \\
\hline \multirow{4}{*}{2} & Video statistics & $\begin{array}{l}\text { Total number of videos. } \\
\text { Average upload of videos to the channel. } \\
\text { Average duration of the videos. }\end{array}$ \\
\hline & Features of the videos & $\begin{array}{l}\text { Typology of the videos. } \\
\text { Type of language used by the edutuber. }\end{array}$ \\
\hline & Channel options & $\begin{array}{l}\text { Channel head. } \\
\text { Home panel. } \\
\text { Active comments. } \\
\text { Links to other channels. } \\
\text { Playlists. } \\
\text { Community function. } \\
\text { Store function. } \\
\text { Patronage and donations. }\end{array}$ \\
\hline & Other social networks & $\begin{array}{l}\text { Twitter. } \\
\text { Instagram. } \\
\text { Facebook. }\end{array}$ \\
\hline
\end{tabular}

Source: Own elaboration

\section{Results}

\subsection{Channel statistics}

The number of subscribers of the analysed channels respond to the following ranges: 1,000 - 10,000 subscribers (46.2\%), 10,000 - 100,000 subscribers (30.8\%), $100,000-1$ million subscribers (20.5\%), and more than 1 million subscribers $(2.5 \%)$. 
In addition, the number of total views that our sample has is as follows: $300,000-1$ million views (28.2\%), 1 million - 5 million views (41\%), 5 million - 10 million views $(7.7 \%), 10$ million - 50 million views (12.8\%), and more than 50 million views $(10.3 \%)$.

On the other hand, the channel creation dates and the start dates of uploading the videos to the YouTube channel are shown in Table 3, while the trend in Figure 1:

Table 3

Correspondence by ranges of years between the channel creation date and the start of uploading the videos

\begin{tabular}{llll}
\hline Years & $2005-2010$ & $2011-2015$ & $2016-2020$ \\
\hline Channel creation & $35.9 \%$ & $43.6 \%$ & $20.5 \%$ \\
$\begin{array}{l}\text { Start of uploading } \\
\text { videos }\end{array}$ & $12.8 \%$ & $59 \%$ & $28.2 \%$ \\
\hline
\end{tabular}

Source: Own elaboration

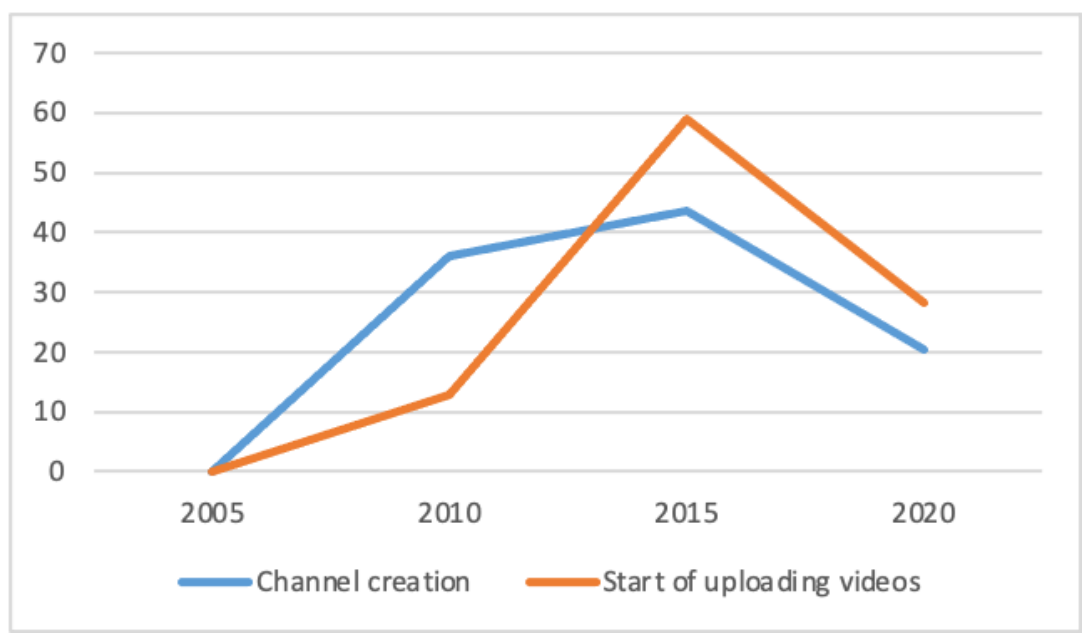

Figure 1. Trend of educational YouTube channels in the Art and Culture area

Differences are evidenced with respect to educational channels from other areas that point towards a greater creation of educational YouTube channels on Art and Culture in the range of years from 2005 to 2010. In addition, there are also differences that show that, in the last range of years, from 2016 to 2020, there are fewer YouTube channels that have started uploading videos on those dates in the Art and Culture area compared to other areas of knowledge. 


\subsection{Video statistics}

The total number of videos hosted by our sample is as follows: 11 - 50 videos (28.2\%), 51 - 100 videos (20.5\%), 101 - 1,000 videos (48.7\%), and more than 1,000 videos $(2.6 \%)$. No channel can be found that, meeting the requirements of the sample, has between 1 and 10 videos on its channel. In addition, the average upload of videos to the channel is as follows: at least once a week $(20.5 \%)$, once every two weeks $(23.1 \%)$, once a month (33.3\%), once every two months (5.1\%) and every more than two months $(18 \%)$. In this area, there are statistically significant differences $(p=$ .014) that indicate a greater number of Art and Culture channels that upload videos every more than two months compared to the average upload of videos to educational channels in other areas.

Regarding the average duration of the videos on the channels, we found the following results: less than 5 minutes (61.5\%), between 5 and 10 minutes $(17.9 \%)$, between 10 and 30 minutes (20.5\%), and there is no Art and Culture channel whose average duration of the videos is more than 30 minutes. There are statistically significant differences $(p=.003)$ that point to a greater use of videos with a duration of less than 5 minutes in the Art and Culture channels.

\subsection{Features of the videos}

The results of our research concerning the characteristics of the videos on YouTube channels in the Art and Culture area can be classified into the following typologies: explanatory $(41 \%)$, examples or experiences $(30.8 \%)$, songs $(12.8 \%)$, tutorials (5.1\%) and without a well-defined typology (10.3\%).

There are statistically significant differences $(p<.001)$ that show a lower choice by the Art and Culture edutubers in the use of explanatory videos. In addition, there is a greater choice on the part of YouTube content creators in this area of the use of videos of songs and examples and experiences.

On the other hand, the language used by the edutubers of the sample responds to the following classification: normal $(66.7 \%)$, infantile $(12.8 \%)$, academic $(5.1 \%)$, youthful $(2.6 \%)$ or they do not use it $(12.8 \%)$. There are statistically significant differences $(p<.001)$ that indicate a greater use by Art and Culture edutubers of a children's language, and of the choice not to use either spoken or written language in their videos. Additionally, the 39 YouTube channels in the sample do not use inappropriate language or profanity within their videos. 


\subsection{Channel options}

The educational channels of Art and Culture belonging to our sample use the channel header to link the audience with other pages or social networks in $69.2 \%$ of the cases.

On the other hand, the home panel offered by these successful channels propose the following options: the last video uploaded to the channel $(41 \%)$, a popular video of the channel $(35.9 \%)$, a video presentation to the channel $(20.5 \%)$, or a specific playlist (2.6\%), while we did not find any channel that chooses the option to show a video of appreciation to the audience in its home panel for having achieved a significant number of subscribers.

In addition, 28 of the 39 channels analysed have the possibility of commenting on their videos activated, 21 channels offer the possibility of linking directly with other channels marked by the edutuber, and 33 channels publicly expose playlists on themes of the Art and Culture area.

Likewise, the Community function is used by content creators on a recurring basis $(25.7 \%)$, occasionally $(12.8 \%)$, or they do not use it $(61.5 \%)$. There are statistically significant differences $(p=.001)$ that indicate less occasional use of the Community function by Art and Culture edutubers compared to their counterparts in other areas, and an increase in the choice not to use this possibility from the YouTube platform.

The Store function is used by one channel of the sample, while 6 channels offer for the audience the possibility of financial donations or patronage to the channel.

\subsection{Other social networks}

YouTube content creators in the Art and Culture area are also present on other social networks: $71.8 \%$ are on Twitter, $64.1 \%$ are on Instagram, and $74.4 \%$ are on Facebook.

\section{Discussion}

Firstly, the characterization of the sample shows a gender gap in YouTube educational channels in the Art and Culture area, where 2 out of 3 edutubers are men, corroborating other research on youtubers (Regueira et al. 2020). We conclude, therefore, that empowerment and training projects should be proposed to achieve 
equality in terms of the representation of sex in the area of Art and Culture on YouTube (Pattier 2021B).

In addition, we observe a clear tendency for edutubers in this area to try to reach a general audience (Parrish 2016) and not to specific educational stages, which shows a trend of success in the area of the dissemination of Art and Culture through platforms such as YouTube, in line with research on content creators from other areas (VizcaínoVerdú et al. 2020). On the other hand, it is important to point out that, among the Art and Culture channels aimed specifically at a specific educational level, the stage of early childhood education stands out to a greater extent. This may indicate that, as students grow, their education in the area of Art and Culture dissipates, while that of other areas, such as Science, increases (Pattier 2021C).

Secondly, and responding to our first research question on the impact and projection of the educational channels in our area of study, this research shows that the quantitative impact is high, corroborating other papers on the subject (Pattier 2021A; Rangarajan et al. 2019). If we take into account the educational channels that exceeded the parameters of success required by the research, practically 2 out of 10 are clearly dedicated to the area of Art and Culture. We can conclude that Art and Culture are achieving a successful dissemination mode through the YouTube platform. From a qualitative point of view, another type of investigation would be needed to corroborate this impact.

On the other hand, the number of subscribers indicates that almost half of the sample is concentrated in the first range analysed, that is, they have between 1,000 and 10,000 subscribers. This shows that there is a great variety of themes within the Art and Culture area that make quite a few channels manage to establish themselves as channels of success, but perhaps this area does not have too many references that achieve a very high number of channel followers. In addition, the number of views of the channels in our sample indicates a tendency to exceed one million, but shows a difficulty of exceeding 5 million. We conclude, therefore, that YouTube educational channels in the Art and Culture area should promote their internationalization and dissemination as an effective methodology to improve their impact (Pattier 2021A).

The trend of educational YouTube channels can be measured by analysing the statistics (Saurabh \& Gautam 2019), offered by the data on the date of creation of the channel and on the start of uploading the videos to the channel. In this way, and thanks to Figure 1, we can see that the trend was very positive until 2015, but, in the last range of years (2016-2020), the trend shortened and fell. This may be due to the 
fact that the educational channels of Art and Culture take time to achieve a significant number of subscribers and views, or that the trend in the creation of audiovisual resources in the Art and Culture area is suffering a negative projection, due, among others factors, to the launch of other platforms, pages and applications that make the disseminators of this area not concentrate their presence on YouTube but rather find themselves dispersed among the various possibilities that technology and its respective applications propose for the Art and Culture area such as Instagram.

Thirdly, and responding to our second research question on the behaviour of edutubers in the Art and Culture area within the YouTube platform and on other social networks, we can affirm that these content creators host a considerable number on their respective channels of resources, where practically half of these channels have between 101 and 1,000 videos. In addition, the average video upload is quite distributed among the channels in this area, which shows that, at least in terms of Art and Culture, it does not determine a clear factor of success. However, it stands out that, compared to channels in other areas, there are significant differences that indicate the existence of more Art and Culture channels that publish videos with an average of more than two months. This shows that there are channels in this area that are not regularly conducted by edutubers and, therefore, reinforces the hypothesis that there is a negative trend in the impact of YouTube channels in this area, as we have noted above.

On the other hand, there is a trend for Art and Culture edutubers to create content of a short duration of time, with a clear predisposition to uploading content of less than 5 minutes. This corroborates other research that indicate the preference or the success factor of short videos in the educational field (Alpert \& Hodkinson, 2019; Long et al., 2016; Pattier 2021A).

Regarding the characteristics of the videos, our research shows that there is a tendency for edutubers in this area to choose an explanatory typology (Margoniner et al. 2019; Pattier 2021A), used in 4 out of 10 channels, and to offer examples and experiences (Tiernan \& O'Kelly 2019), implemented by 3 out of 10 channels. These two types, therefore, can be considered successful for the educational YouTube channels of Art and Culture. In addition, we observe that this very special area of knowledge offers many possibilities in terms of the typology of the videos, demonstrating a greater use, for example, of songs or of examples and experiences than their counterparts in other areas. Therefore, we observe that there is a diversity 
and creativity (Duncum 2018) inherent in the area of Art and Culture reflected in the choice of the typology of audiovisual resources of this subject.

Likewise, the data show a trend on the part of Art and Culture edutubers in the use of a normal language, corroborating other research on the subject (Long et al. 2016; Pattier 2021A; Rodgers et al. 2020), which makes the resources can be accessible to the general public (Vizcaíno-Verdú et al. 2020) and not only to certain professionals of the defined topics. On the other hand, an attempt by edutubers in this area is demonstrated to reach, largely than their counterparts in other areas, a child audience (Neumann \& Herodotou 2020), using a language more appropriate to them.

The options chosen by the edutubers regarding the presentation of the channel to the audience are important since they show the behaviour of the content creators in the process of uploading and disseminating their audiovisual resources. In this way, we can see that practically 7 out of 10 Art and Culture youtubers offer the option of connecting with other pages or social networks in which the content creator is present at the head of the channel. Moreover, we can appreciate an attempt by edutubers in this area to connect with the audience from other platforms and technological applications other than YouTube.

On the other hand, the data shows the preference of content creators for the use in their home panel of the last video uploaded to the channel, or a popular channel of the channel. We conclude that these two options are established as a success factor for educational YouTube channels in the Art and Culture area.

The variable offered by 7 out of 10 channels in this area of the possibility of commenting on their videos stands out. If we take into account that YouTube keeps this possibility restricted to channels dedicated to a child audience, and that, as we have indicated, there is a part of our sample that shows an attempt to reach an audience of these ages, we can conclude that the possibility of commenting on videos is activated in the vast majority of the Art and Culture channels that the platform allows it to because they are not directly focused on a child audience. This shows a tendency to establish a connection with the audience and be able to receive direct feedback from users (Pattier 2021A; Xiao 2017). However, the Community function is rarely used by edutubers in this area. Therefore, taking into account that this new functionality began in 2016 (last range of years analysed), we conclude that there are a large number of Art and Culture channels in which there is no recurrent monitoring by the creator, which increases the possibility of a negative trend in the impact of the 
channels, as we have previously announced, or the possible lack of time to dedicate to the channel by edutubers (Pattier 2021B).

On the other hand, there are three ways to obtain remuneration through the YouTube platform. Firstly, through the monetization of the channel, the impact of which depends, largely, on the views obtained by the videos. Secondly, through the Store function, where edutubers can offer the audience the purchase of articles related to the channel, and which, as we see in the results, is only used by one channel in the sample. Thirdly, YouTube offers the possibility of establishing patronage or issuing a donation to the channel by the audience through platforms and pages such as Patreon (Wilson \& Wu 2020) or PayPal, an option used by $15 \%$ of the channels analysed. Therefore, we conclude that there is a clear trend that audiovisual content creators in the Art and Culture area do not use YouTube as a private means of profit, but rather that a spirit of altruism is reflected in the creation of audiovisual educational resources and in their subsequent free upload to the audience (Pattier 2021C).

Regarding the presence of YouTube content creators on other social networks (Closson \& Bond 2019), we can observe a trend towards the use of several platforms at the same time to maintain contact with the audience or to participate in groups in which to share their work or comment on questions about the topics they address. Moreover, we observe that this presence is focused, above all, on Facebook and Twitter (Staudt Willet 2019), while it drops a bit on Instagram, probably due to the fact that the age range of the Art and Culture edutubers makes it more conducive their presence on Facebook and Twitter, while Instagram tends to welcome a relatively younger audience.

\section{Conclusions}

Thanks to the analysis of our research data, and answering our first research question, we can conclude that YouTube's educational channels in the Art and Culture area have a high impact on informal education today, at least from a quantitative point of view. However, it highlights a necessary improvement in the dissemination and internationalization of the videos of the channels to improve this impact. In addition, there is a downward trend in the creation of channels and audiovisual resources in this area, which shows a negative outlook, if the current trend continue.

Therefore, and answering our second research question, we can conclude that Art and Culture edutubers usually create content designed for an audience, on the one hand, general, and on the other, children. They use short videos, with an explanatory 
typology or examples and experiences, and using normal and children's language. Moreover, they seek a connection with the audience through the comments of the videos but there is a lack of recurrent follow-up by the edutubers. In addition, there is an altruistic spirit on the part of the content creators in this area.

Likewise, a presence of Art and Culture youtubers is demonstrated in other social networks, promoting interaction with the audience through the possibilities offered by other platforms. The order of preference for content creators in the Art and Culture area of other social networks is as follows: Facebook, Twitter and Instagram.

Finally, this research shows a gender gap in the edutubers of this area of knowledge, which must be investigated mostly in order to achieve, in an efficient way, equality in this group with a high social and educational impact.

This research provides insights, first, to education professionals who use videos as resources for their classes, second, to YouTube educational content creators, and third, to those in charge of establishing teacher training plans, providing evidence on the need to know the success factors of educational audiovisual resources in order to implement them efficiently in the teaching-learning process.

The prospective of this research is in the internationalization of the sample and the comparison of results with educational channels of the same subject outside the Spanish national scene. On the other hand, the COVID-19 pandemic significantly affected the world of education and the use of asynchronous resources such as YouTube videos. Therefore, it will be important to carry out new research on the subject once the pandemic has passed and after a period of stabilization, in order to identify possible changes in the trend regarding the impact or projection of the educational YouTube channels in the Art and Culture area. 


\section{References}

Alpert, F., \& Hodkinson, C. S. (2019). Video use in lecture classes: Current practices, student perceptions and preferences. Education and Training, 61(1), 31-45.

Beheshti, M., Taspolat, A., Kaya, O. S., \& Sapanca, H. F. (2018). Characteristics of instructional videos. World Journal on Educational Technology: Current Issues, 10(1), 61-69.

Beltrán-Pellicer, P., Giacomone, M. B., \& Navarro, M. B. (2018). Online educational videos according to specific didactics: The case of Mathematics. Culture and Education, 30(4), 633-662.

Clark, J. C., Sauceda, J., \& Stormes, S. (2019). Faculty Format Preferences in the Performing Arts: A Multi-Institutional Study. College \& Research Libraries, 80(4), 450-469.

Closson, L. M., \& Bond, T. A. (2019). Social network site use and university adjustment. Educational Psychology, 39(8), 1027-1046.

Díaz, A. L., Moreno, M. J. G., \& Piqueras, C. C. (2020). Youtube como recurso didáctico en la Universidad. EDMETIC, 9(2), 159-180.

Duncum, P. (2018). Responding to Big Data in the Art Education Classroom: Affordances and Problematics. International Journal of Art \& Design Education, $37(2), 325-332$.

Esparza Puga, D. S. (2018). Uso autónomo de recursos de Internet entre estudiantes de ingeniería como fuente de ayuda matemática. Educación Matemática, 30(1), 73-91.

Fenyvesi, K. (2020). English learning motivation of young learners in Danish primary schools. Language Teaching Research, 24(5), 690-713.

Hopper, J. J. (2016). Digitizing the Easel: Student Perspectives on Tutorial Videos in the Art Classroom. Art Education, 69(4), 23-28.

Laugerman, M. R., \& Saunders, K. P. (2019). Supporting student learning through instructional videos in business statistics. Decision Sciences Journal of Innovative Education, 17(4), 387-404.

Long, T., Logan, J., \& Waugh, M. (2016). Students' perceptions of the value of using videos as a pre-class learning experience in the flipped classroom. TechTrends, 60(3), 245-252.

López, J. L., Maza-Córdoba, J., \& Tusa, F. (2020). Educar en el contexto digital: el reto de ser edutuber. Revista Ibérica de Sistemas e Tecnologias de Informação, (E25), 188-200. 
Macias-Silva, E. C., Aquino-Rojas, M. A., Rodríguez-Pillajo, L. A., \& Heredia-Arboleda, E. E. (2020). Impact of ICT on virtual learning. Dominio de las Ciencias, 6(3), 1065-1076.

Margoniner, V., Bürki, J., \& Kapp, M. (2019). Monkeying Around in Mechanics: Using Student-Student Dialogue Videos to Increase Physics Learning. The Physics Teacher, 57(4), 232-235.

Neumann, M. M., \& Herodotou, C. (2020). Evaluating YouTube videos for young children. Education and Information Technologies, 25(5), 4459-4475.

Parrish, M. (2016). Toward Transformation: Digital Tools for Online Dance Pedagogy. Arts Education Policy Review, 117(3), 168-182.

Pattier, D. (2021A). Educational leaders during the COVID-19 pandemic: The success of the edutubers. PUBLICACIONES, 51(3), 533-563.

Pattier, D. (2021B). The Gender Gap Among EduTubers and the Factors Significantly Influencing It. Journal of New Approaches in Educational Research, 10(2), 313329.

Pattier, D. (2021C). Science on Youtube: Successful Edutubers. TECHNO REVIEW. International Technology, Science and Society Review, 10(1), 1-15.

Ranga, J. S. (2017). Customized Videos on a YouTube Channel: A Beyond the Classroom Teaching and Learning Platform for General Chemistry Courses. Journal of Chemical Education, 94(7), 867-872.

Rangarajan, K., Begg, K., \& Somani, B. (2019). Online digital media: the uptake of YouTube-based digital clinical education (DCE). American Journal of Distance Education, 33(2), 142-150.

Regueira, U., Alonso-Ferreiro, A., \& Da-Vila, S. (2020). Women on YouTube: Representation and participation through the Web Scraping technique. Comunicar, 28(63), 31-40.

Rodgers, T. L., Cheema, N., Vasanth, S., Jamshed, A., Alfutimie, A., \& Scully, P. J. (2020). Developing pre-laboratory videos for enhancing student preparedness. European Journal of Engineering Education, 45(2), 292-304.

Rosenthal, S. (2018). Motivations to seek science videos on YouTube: Free-choice learning in a connected society. International Journal of Science Education, Part $B, 8(1), 22-39$.

Sarkar, N., Ford, W., \& Manzo, C. (2019). To flip or not to flip: What the evidence suggests. Journal of Education for Business, 95(2), 81-87. 
Saurabh, S., \& Gautam, S. (2019). Modelling and statistical analysis of YouTube's educational videos: A channel Owner's perspective. Computers \& Education, 128, 145-158.

Srinivasacharlu, A. (2020). Using YouTube in colleges of education. Shanlax International Journal of Education, 8(2), 21-24.

Staudt Willet, K. B. (2019). Revisiting how and why educators use Twitter: Tweet types and purposes in \#Edchat. Journal of research on technology in education, 51(3), 273-289.

Tiernan, P., \& O'Kelly, J. (2019). Learning with digital video in second level schools in Ireland. Education and Information Technologies, 24(2), 1073-1088.

Veytia Bucheli, M. G., Gladiola Flores, L., \& Moreno Tapia, J. (2020). Clase invertida para el desarrollo de la competencia: uso de la tecnología en estudiantes de preparatoria. Revista Educación, 44(1), 192-209.

Vizcaíno-Verdú, A., De-Casas-Moreno, P., \& Contreras-Pulido, P. (2020). Divulgación científica en YouTube y su credibilidad para docentes universitarios. Educación $X X 1,23(2), 283-306$.

Wilson, L., \& Wu, Y. W. (2020). Crowdfunding on Patreon by YouTube sailing channels. SSRN, 1-32:

Xiao, J. (2017). Learner-content interaction in distance education: The weakest link in interaction research. Distance Education, 38(1), 123-135.

Zureick, A. H., Burk-Rafel, J., Purkiss, J. A., \& Hortsch, M. (2018). The interrupted learner: How distractions during live and video lectures influence learning outcomes. Anatomical Sciences Education, 11(4), 366-376. 